\section{The diverse issues of Healthcare in Low-resource Settings}

\section{Asfandyar Khan Niazi \\ College of Medicine, Dentistry and Nursing, University of Dundee, UK}

This first issue of the Healthcare in Lowresource Settings (HLS) includes several papers on diverse topics. Among the many interesting papers published in this issue, some are briefly summarized here. The paper by Jargin discusses the barriers to the import of medical products to Russia, problems resulting thereof and presents forth some possible solutions. ${ }^{1}$ The author highlights the consequences of widespread red-tape and corrupt practices in the current Russian import systems and argues that such practices have led to an isolation of Russia from the rest of the medical world.

Shrivastava et al. in their paper ${ }^{2}$ describe the inadequate healthcare services for the indigenous tribes of India and the inequitable distribution of healthcare resources between the indigenous and non-indigenous population. The authors present several practical and implementable ways to improve the health status of the indigenous tribes.

Purohit used a mathematical model to evaluate the differences in the healthcare behaviors between rural and urban, and private and public healthcare providers in India. ${ }^{3}$ By using the data from the National Family Health Survery - 3 of India, the author found significant disparities between rural and urban areas, with important public health policy implications.

Olugbile et al. used a retrospective chart review to study the cost of treatment of patients with psychiatric diseases in the Nigerian population. ${ }^{4}$ On the basis of the records of 100 psychiatric patients, the researchers found that the cost of treatment of medical patients was much higher than psychiatric patients (Nigerian naira 2549.07 vs 1904.5, $\mathrm{P}<0.05$ ). However the researchers found that Nigeria does not have any free psy- chiatric health program. They, therefore, identified the absence of free mental healthcare as a barrier to psychiatric healthcare utilization.

Mosha et al. used a cross-sectional study based on face to face questionnaires to assess the adequacy of healthcare facilities offering male circumcision in Tanzania. ${ }^{5}$ They compared the standards currently being followed in Tanzania with the standards recommended by the World Health Organization. The researchers found a shortage of sterilization and research equipment in the healthcare centers offering male circumcision.

In another report from India, Kumar and Mahapatro performed a qualitative study using interviews with the auxillary nurse midwives. ${ }^{6}$ The researchers evaluated the role of sociocultural factors on the acceptance of midwives, as reported by the midwives, working in the rural community of India. Several sociocultural factors were identified by the researchers that impede the acceptance of these midwives in the villages which points towards the need to strengthen their position in their work places.

A cross-sectional study from Egypt conducted by Mohamed assessed the factors motivating healthcare workers to work in rural areas. ${ }^{7}$ The researchers conducted interviews of 302 medical students and found that a high parental professional and educational status was associated with a lower willingness to work in rural areas. However a significant portion of the study participants were interested in working in the rural areas.

The issue also includes several other interesting articles that we invite you to read.

\section{References}

1. Jargin SV. Barriers to the importation of medical products to Russia: in search of solutions. Healthcare in Low-resource Settings 2013;1:e13.

2. Shrivastava SR, Shrivastava PS, Ramasamy J. Implementation of public health practices in tribal populations of India: challenges and remedies. Healthcare in Low-resource Settings
Correspondence: Asfandyar Khan Niazi, College of Medicine, Dentistry and Nursing, University of Dundee, George Pirie Way, Dundee, UK.

Tel/Fax: +44.1382.381600

E-mail: editor@hlsjournal.org

Key words: healthcare, low-resource settings, editorial.

Conflict of interests: the author declares no potential conflict of interests.

Received for publication: 1 August 2013. Accepted for publication: 1 August 2013.

This work is licensed under a Creative Commons Attribution 3.0 License (by-nc 3.0).

(C)Copyright A.K. Niazi, 2013

Licensee PAGEPress, Italy

Healthcare in Low-resource Settings 2013; 1:e15 doi:10.4081/hls.2013.e15

2013;1:e3.

3. Purohit BC. Demand for healthcare in India. Healthcare in Low-resource Settings 2013;1:e7.

4. Olugbile OB, Coker AO, Zachariah MP. Cost of treatment as a barrier to access and continuity of healthcare for patients with mental ill-health in Lagos, Nigeria. Healthcare in Low-resource Settings 2013; 1:e8.

5. Mosha FF, Wambura M, Mwanga JR, et al. Readiness of health facilities to deliver safe male circumcision services in Tanzania: a descriptive study. Healthcare in Low-resource Settings 2013;1:e9.

6. Kumar A, Mahapatro M. The cutting edge in the blunt space: an anthropological construct of auxiliary nurse midwives' social world in the community. Healthcare in Low-resource Settings 2013;1:e10.

7. Mohamed AM. Willingness and professional motivations of medical students to work in rural areas: a study in Alexandria, Egypt. Healthcare in Low-resource Settings 2013;1:e4. 